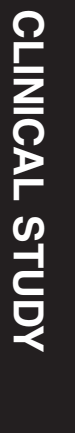

${ }^{1}$ Unidad Periferica de Neurociencias, Facultad de Medicina, UNAM/Instituto, Nacional de Neurologia y Neurocirugia 'Manuel Velasco Suarez', Mexico City, Mexico

${ }^{2}$ Department of Cornea and Refractive Surgery, Institute of Ophthalmology Conde de Valenciana, Mexico City, Mexico

${ }^{3}$ Centro de Atencion Integral del Paciente con Diabetes, Instituto Nacional de Ciencias Medicas y Nutricion 'Salvador Zubiran', Mexico

City, Mexico

${ }^{4}$ Posgrado de Neuroetologia, Universidad Veracruzana, Mexico City, Mexico

${ }^{5}$ Departamento de Fisiologia, Facultad de Medicina, UNAM, Mexico City, Mexico

Correspondence:

EO Graue-Hernandez, Department of Cornea and Refractive Surgery, Institute of Ophthalmology Conde de Valenciana,

Chimalpopoca Street, Mexico City 06800, Mexico Tel: +52 5555884600 ext. 3710;

Fax: +52 5554421700 .

E-mail: egraueh@gmail.com

Received: 12 July 2016 Accepted in revised form: 31 May 2017

Published online:

11 August 2017

\title{
Ophthalmic features of spinocerebellar ataxia type 7
}

\begin{abstract}
Purpose To analyze the relation between ophthalmologic and motor changes in spinocerebellar ataxia type 7 (SCA7).

Patients and methods This was a case series study. Sixteen SCA7 patients underwent a comprehensive ophthalmic examination, including ocular extrinsic motility testing, color vision test, and optical coherence tomography of the optic nerve and macula. Changes in the corneal endothelium, electroretinographic patterns, and a complete neurologic evaluation using the Scale for the Assessment and Rating of Ataxia (SARA) were evaluated. Correlations of endothelial cell density (ECD) with number of CAG repetitions and the SARA scores were estimated.
\end{abstract}

Results All patients showed various degrees of visual impairment mainly due to macular deterioration. Notably, they also presented decreased ECD. Pairwise correlations of ECD with number of CAG repeats and severity of motor symptoms quantified with the SARA scores were inverse $(r=-0.46, P=0.083$ and $r=-0.64, P=0.009$, respectively). Further analyses indicated an average ECD decrease of 48 cells $/ \mathrm{mm}^{2}(P=0.006)$ per unit of change on the number of CAG repeats, and of 75 cells $/ \mathrm{mm}^{2}(P=0.001)$ per unit of change on the SARA scores.

Conclusions The results agree with previous ophthalmological findings regarding the widespread effect of SCA7 mutation on the patient's visual system. However, the results also show a significant negative correlation of decreased ECD with both CAG repetitions and SARA scores. This suggests that motor systems could degenerate in parallel with visual systems, although more research is needed to determine whether the degeneration is caused by the same mechanisms.

Eye (2018) 32, 120-127; doi:10.1038/eye.2017.135; published online 11 August 2017
A Campos-Romo', EO Graue-Hernandez², L Pedro-Aguilar², JC Hernandez-Camarena ${ }^{2}$, D Rivera-De la Parra ${ }^{2,3}$, V Galvez ${ }^{1,4}, \mathrm{R} \mathrm{Diaz}^{5}$, A Jimenez-Corona ${ }^{2}$ and J Fernandez-Ruiz ${ }^{4,5}$

\section{Introduction}

The spinocerebellar ataxias (SCAs) are autosomal dominant inherited progressive neurodegenerative disorders clinically characterized by progressive loss of coordination in gait and limb movements. ${ }^{1}$ They are also associated with variable additional symptoms, including dysarthria, dysphagia, pyramidal and extrapyramidal signs, and dementia.

Ophthalmological findings are often limited to impaired ocular motility and retinopathy in some SCA types. ${ }^{2,3}$ Pathologically, SCAs are typified by prominent atrophy of the cerebellum, brainstem, and spinal cord, with different degrees of cerebral cortex and basal ganglia degeneration. ${ }^{4}$

Besides motor symptoms, SCA 7 (SCA7) patients show progressive visual impairment. ${ }^{5}$ Their central vision is compromised first and eventually the condition evolves toward severe visual loss. ${ }^{6}$ Impairment of the tritan axis (blueyellow) color vision can also be detected in these patients; in fact, it might be present years before visual failure is noticed. ${ }^{7}$ Degenerative changes in the retina initially affect the central macula, and in latter stages, they damage the peripheral retina. ${ }^{8}$ Fundoscopy reveals an early loss of normal foveal reflex, followed by granular pigmentation of the macula interspersed with pale areas of retinal pigment epithelium (RPE) atrophy. Histological analyses show a complete absence of photoreceptors, severe loss of ganglion cell neurons, and thinning of both nuclear and plexiform layers. Moreover, some authors have described migration of melanin pigment from the retinal epithelium toward the atrophic retina. ${ }^{4}$ In addition, recent studies have reported retinal thinning with loss of the peripapillary retinal nerve fiber layer, as demonstrated by optical coherence tomography (OCT), reduced amplitudes in multifocal electroretinogram (ERG), reduced $30 \mathrm{~Hz}$ flicker cone amplitudes in the full-field ERG, ${ }^{9}$ and 
decreased corneal endothelial cell count when compared with that expected for age. ${ }^{10}$

In this study, we describe the results of the ophthalmological analysis of a large group of patients with genetically confirmed SCA7, and their relation with motor deterioration.

\section{Materials and methods}

This research followed the principles of the Declaration of Helsinki and was approved by the ethics committees of the Instituto de Oftalmologia 'Conde de Valenciana', Instituto Nacional de Neurologia y Neurocirugia 'Manuel Velasco Suarez', and Facultad de Medicina, UNAM. All participants were informed on the aims of the study and gave their informed consent to clinical and genetic analysis.

\section{Participants}

We identified seven families who resided in a circumscribed community of Veracruz, a Mexican southeastern state with a high incidence of the disease in this region due to a founder effect. ${ }^{11}$ For the present study, we included 16 subjects; four females and 12 males (median age 38 years, range 20-66). In all cases a neurological assessment, ophthalmological examination and genetic analysis were performed.

\section{Neurological examination}

Participants were evaluated using a standard protocol recording sex, age at onset, duration of the disease, and clinical manifestations (such as cerebellar ataxia, movement disorders, pyramidal signs, peripheral nerve signs, cognitive dysfunction, or epilepsy). Ataxiaassociated symptoms were determined with the Scale for the Assessment and Rating of Ataxia (SARA). ${ }^{12}$

\section{Ophthalmic examination}

All cases underwent a comprehensive ophthalmic examination including uncorrected and corrected distance visual acuity (UDVA and CDVA, respectively) using Snellen charts (for analysis, visual acuity (VA) was converted to LogMAR units), ocular extrinsic motility testing, slit-lamp biomicroscopy of the anterior segment, fundoscopy and measurement of intraocular pressure, and color vision evaluation with Ishihara color plates.

The anterior segment was analyzed with corneal tomography using the Pentacam Scheimpflug system (Oculus, Weltzar, Germany). Endothelial analysis was performed using a specular microscope 'FA-3509' ROBO Noncon Series (Konan Medical USA, Inc., CA, USA). To improve accuracy, three different measurements in five different corneal locations were taken (one in each quadrant and central $3 \mathrm{~mm}$ ) and values were averaged. Endothelial cell density (ECD), polymegethism (measured using the coefficient of variation), and pleomorphism (percentage of hexagonality of cells) were also measured. The characterization of ECD and morphology were compared with normal Mexican population, ${ }^{13}$ criteria used to determine abnormality was 1 SD above or below the mean.

The retina was examined with clinical pictures and OCT. Fundus photography was performed using a FF 450 fundus camera (Carl Zeiss Meditec, Jena, Germany); 50 pictures focused in the macula were acquired. Retinal findings in clinical photographs were classified (Figure 1) as mild (loss of foveal reflex), moderate (granular appearance and/or pigment changes of the RPE), and severe (clinically evident atrophy). Foveal and parafoveal retinal thickness as well as retinal layers structure were analyzed with a spectral domain-OCT (Spectralis, Heidelberg Engineering Inc., Heidelberg, Germany). A certified retina specialist evaluated OCT scans, description of the OCT included the status of the fovea, ellipsoid layer and RPE integrity.

The evaluation of the optic nerve was performed under pharmacological mydriasis to obtain information about disc area, cup area, neuroretinal rim area, and cup/disc ratio, using a Heidelberg Retina Tomograph (HRT) Glaucoma Module (Heidelberg Engineering $\mathrm{GmbH}$ ).

Electroretinographic analysis was performed with either a Vision Monitor Visual Electroretinography System (Metrovision, Pérenchies, France) or a CSO Costruzione Strumenti Oftalmici Retimax electroretinography system (Firenze, Italy), following the standards, recommendations and guidelines established by the International Society for Clinical Electrophysiology of Vision (ISCEV). Rods responses, maximum combined response and oscillatory potentials were measured after $20 \mathrm{~min}$ of scotopic adaptation. Cone responses (single flash) and rapid responses to a repeated stimulus (flicker) were recorded after $10 \mathrm{~min}$ of photopic adaptation. Values were graded as normal (amplitude $<1 \mathrm{SD}$ ), borderline (diminished, 1-2 SD), abnormal (severely diminished $>2 \mathrm{SD}$ ), or not recordable (abolished, isoelectric line) according to the pre-established manufacturer values for the ERGs.

\section{Genetic diagnosis}

All cases were genetically confirmed with SCA7. Haplotype analysis of microsatellite markers (D3S1228, D3S1287, and D3S3635) and an intragenic singlenucleotide polymorphism (SNP) (3145G/A), spanning the 5.21-cM region of chromosome $3 p$ harboring the ATXN7 

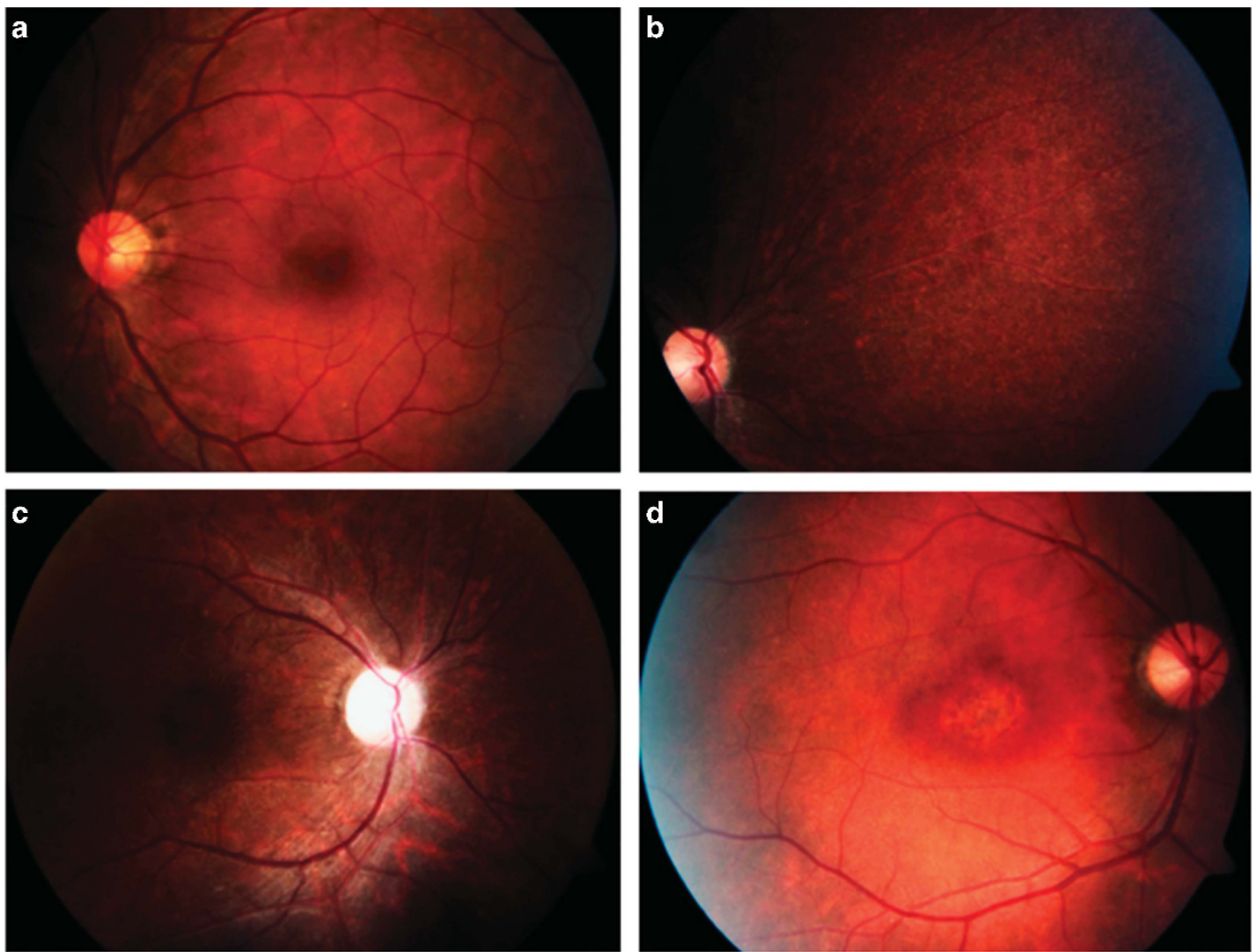

Figure 1 The spectrum of the disease varied from mild to severe, as shown in the color fundus photographs. (a) Subtle pigment changes in the fovea. (b) Mottled hypopigmentary spots in peripheral retina and vascular attenuation. (c) Macular degeneration (annular atrophic lesion) with increased visibility of choroidal vessels. (d) Foveal atrophy with surrounding pigment changes.

gene $^{14}$ were amplified by PCR and analyzed on the ABI Prism 310 sequencer (Applied Biosystems, Foster City, CA, USA). The internal GeneScanTM 500HD (tetramethyl-6-carboxyrhodamine (ROX) dye) Size Standard (PerkinElmer (PE)-Applied Biosystems) was included for determining the size of each allele. Alleles were arbitrarily denominated according to their size in base pairs (bp). The SNP marker was analyzed using the 5' exonuclease-based real-time PCR assay on the StepOneTM Thermal Cycler (PE-Applied Biosystems). ${ }^{15}$

\section{Statistical analysis}

Percentages and means were used to describe categorical and continuous variables, respectively. Correlations of ECD with number of CAG repetitions and the SARA scores were estimated by partial Pearson correlation (r). To estimate the predicted values of ECD, multiple linear regression analyses were carried out using standard methods. Results are given as regression coefficients $(\beta)$ and their $95 \%$ confidence interval $(95 \% \mathrm{CI})$. All analyses were performed using Stata/MP 12.0 (Stata Corporation, College Station, TX, USA).

\section{Results}

Table 1 displays the subjects' demographic characteristics. Most cases had motor symptoms as initial manifestation (56.25\%, mean age $23.8 \pm 7.6$ years at onset of symptoms); a minority of cases claimed that visual symptoms were the first to appear $(12.5 \%$, mean age $26.0 \pm 7.6$ years). The scores of SARA ranged from 4 to 26 points (mean $13.6 \pm 4.7$ ). The mean of CAG repeats was $48.6+4.6$ (range from 42 to 61 ; Table 2).

\section{Visual acuity, color vision evaluation and ocular motility}

CDVA was decreased in all cases; average Snellen VA was 20/500 (range 20/60 to light perception). Because of low vision, color vision testing with Ishihara pseudoisochromatic color plates was only feasible in 12 subjects, 11 cases were not able to discriminate $(0 / 11$ plates) and one was trichromatic (10/11 plates).

All cases were orthophoric with normal ocular movements. 
Table 1 Demographic characteristics, ophthalmological features, number of CAG repetitions and neurological SARA assessment

\begin{tabular}{|c|c|}
\hline Characteristics & Parameters $^{\mathrm{a}}(\mathrm{n}=16)$ \\
\hline \multicolumn{2}{|l|}{$\operatorname{Sex}$} \\
\hline Male $(n, \%)$ & $12(75 \%)$ \\
\hline Age $^{\mathrm{b}}$ (years) & $38 \pm 12.5$ \\
\hline Age at diagnosis ${ }^{c}$ & $31.8 \pm 10.9$ \\
\hline Age at onset of motor symptoms ${ }^{\mathrm{d}}$ & $23.8 \pm 7.6$ \\
\hline Age at onset of visual symptoms ${ }^{\mathrm{d}}$ & $26.0 \pm 7.6$ \\
\hline \multicolumn{2}{|l|}{ Ophthalmological features } \\
\hline CDVA (logMAR) & $1.43 \pm 0.99$ \\
\hline Mean keratometry (D) & $43.32 \pm 1.93$ \\
\hline Spherical Equivalent (D) & $-0.93 \pm 1.11$ \\
\hline Axial length (mm) & $23.48 \pm 0.70$ \\
\hline \multicolumn{2}{|l|}{ Specular microscopy } \\
\hline Endothelial cell density (cells $/ \mathrm{mm}^{2}$ ) & $2134 \pm 644$ \\
\hline Variation coefficients (\%) & $35.97 \pm 4.6$ \\
\hline Hexagonality $(\%)$ & $53.41 \pm 9.2$ \\
\hline Pachymetry $(\mu \mathrm{m})$ & $531.19 \pm 48.7$ \\
\hline \multicolumn{2}{|l|}{ Optic nerve analysis } \\
\hline Disc area & $1.88 \pm 0.37$ \\
\hline Cup area & $0.40 \pm 0.22$ \\
\hline Cup/disc rate & $0.21 \pm 0.11$ \\
\hline Mean RNFL thickness & $0.22 \pm 0.04$ \\
\hline \multicolumn{2}{|l|}{ Ishihara color test } \\
\hline Abnormal $(n, \%)$ & $11(68.75 \%)$ \\
\hline Normal $(n, \%)$ & $1(6.25 \%)$ \\
\hline Not determined $(n, \%)$ & $4(25 \%)$ \\
\hline \multicolumn{2}{|l|}{ Tomographic macular evaluation } \\
\hline Central macular thickness & $126.9 \pm 17.8$ \\
\hline $\begin{array}{l}\text { Atrophy, loss of the ellipsoid layer, RPE } \\
\text { changes }(n, \%)\end{array}$ & $11(68.75 \%)$ \\
\hline Not Determined $(n, \%)$ & $5(31.25 \%)$ \\
\hline SARA score & $13.6+4.7$ \\
\hline Number of CAG repetitions & $45.6+13.07$ \\
\hline
\end{tabular}

Abbreviations: CDVA, corrected distance visual acuity; D, Diopters; mm, millimeters; RNFL, retinal nerve fiber layer; Abnormal Ishihara color test, absence of identification of any Ishihara card; SARA, Scale for the Assessment and Rating of Ataxia. ${ }^{\mathrm{a}}$ Mean and SD. ${ }^{\mathrm{b}}$ Age at time of study. ${ }^{\mathrm{c}} \mathrm{Age}$ at visit to the neurologist. ${ }^{\mathrm{d}} \mathrm{Age}$ at first experienced symptoms.

\section{Biomicroscopy of the anterior segment}

Slit-lamp examination revealed clear corneas and normal irises in all subjects. However, examination of the lens revealed nuclear opacities in one case (subject number 1).

\section{Corneal power, pachymetry, and corneal endothelial cell analysis}

Average keratometry readings $(\mathrm{Km})$, spherical equivalent $(\mathrm{SE})$, and axial length (AL) are summarized in Table 1. $\mathrm{Km}, \mathrm{SE}$, and $\mathrm{AL}$ were found within normal limits.
Table 2 Endothelial cell density, CAG repetitions and SARA score

\begin{tabular}{lccccc}
\hline Subject & Age & CAG & SARA & \multicolumn{2}{c}{$E C D\left(\text { cells } / \mathrm{mm}^{2}\right)^{\mathrm{b}}$} \\
\cline { 5 - 6 } & & & & OD & OS \\
\hline 1 & 66 & 43 & 14.5 & 2392 & 1942 \\
2 & 48 & 50 & 13 & $1468^{*}$ & $1553^{*}$ \\
3 & 44 & 48 & 11 & $2315^{*}$ & $2257^{*}$ \\
4 & 55 & 46 & 12 & 2410 & 1908 \\
5 & 37 & 52 & 16 & $1621^{*}$ & $1603^{*}$ \\
6 & 35 & 55 & 17 & $1401^{*}$ & $1859^{*}$ \\
7 & 32 & 48 & 12 & $1656^{*}$ & $2066^{*}$ \\
8 & 32 & 48 & 26 & $1009^{*}$ & $1125^{*}$ \\
9 & 23 & 61 & 12.5 & $1631^{*}$ & $1437^{*}$ \\
10 & 47 & 45 & 16 & $1481^{*}$ & $1577^{*}$ \\
11 & 20 & 48 & 12.5 & 3255 & 3208 \\
12 & 21 & 48 & 4 & 3268 & 3058 \\
13 & 37 & 42 & 8.5 & 2890 & 2703 \\
14 & 47 & 44 & 12 & 2899 & $2387^{* *}$ \\
15 & 32 & 52 & 12 & 2681 & 2525 \\
16 & 32 & 49 & 19 & $2311^{* *}$ & 2415 \\
\hline
\end{tabular}

Abbreviations: ECD, endothelial cell density; yo, years old.

Each value was compared with the mean in the Mexican population by age group (Molina-Rey and $\mathrm{Gomez}^{13}$ ) considering abnormal \pm 1 and $2 \mathrm{SD}$. Abnormal results are marked * for values below 2 SD, and with ** for results below only $1 \mathrm{SD}$. ${ }^{\mathrm{a}} \mathrm{Age}$ at time of study. ${ }^{\mathrm{b}} \mathrm{Normal}$ values of ECD by age group (mean and SD cells $/ \mathrm{mm}^{2}$ ): (a) 20-29 yo $2898 \pm 272.9$; (b) 30-39 yo $2672 \pm 294.9$; (c) $40-49$ yo $2608 \pm 94.8$; (d) $50-59$ yo $2055 \pm 445.2$; (e) $60-69$ yo $1978 \pm 349.3$.

Subjects' cell density and morphology was considered abnormal considering $1 \mathrm{SD}$ above or below the mean, using mean values for healthy Mexican population, ${ }^{13}$ Table 2 footnote describe the values used for a normal range by age.

Specular microscopy of the corneal endothelium revealed abnormal ECD in $56.2 \%$ of cases, with mean ECD of $2134 \pm 644$ cells $/ \mathrm{mm}^{2}$ (range 1009-3268). The mean pachymetry was $531.19 \pm 48.7 \mu \mathrm{m}$ (range 417-653). The variation coefficients and hexagonality mean values were $35.97 \pm 4.6 \%$ and $53.41 \pm 9.2 \%$, respectively (Table 1 ).

In pairwise correlations of endothelial corneal cells count with number of CAG repetitions $(r=-0.46$, $P=0.083)$ and the SARA scores $(r=-0.64, P=0.009)$, inverse relations were found. A linear regression model including CAG repetitions and the SARA scores as predictors showed that the average decrease on ECD was $75 \mathrm{cell} / \mathrm{mm}^{2}$ (95\%CI from -113 to $\left.-36.4, P=0.006\right)$ per each unit of change on the CAG repetitions, and 49 cells/ $\mathrm{mm}^{2}(95 \% \mathrm{CI}$ from -80.2 to $-16.8, P=0.001)$ per each unit of change on the SARA scores (Figure 2).

\section{Fundoscopic examination}

Dilated eye examination of the retina and optic nerve did reveal maculopathy with variable degrees of severity in all cases. Common findings were: loss of foveal reflex, granular 
a Correlation between endothelial corneal cells

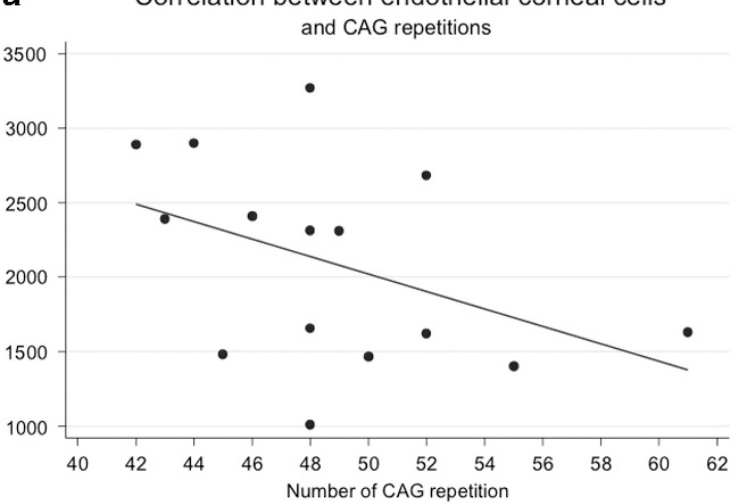

b Correlation between endothelial corneal cells and SARA

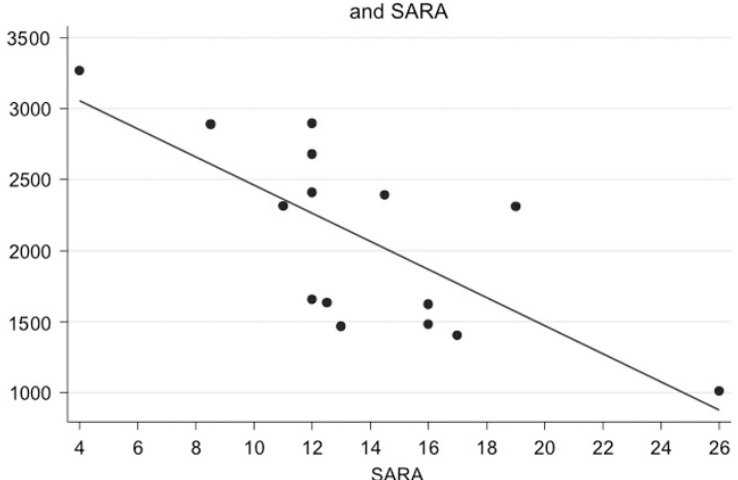

Figure 2 (a) Linear regression model of endothelial cell density (ECD) and CAG repetitions. (b) Linear regression of ECD and SARA.

Table 3 Clinical macular changes and electroretinographic findings ${ }^{\text {a }}$

\begin{tabular}{|c|c|c|c|c|c|c|}
\hline Subject & $\begin{array}{l}\text { Clinical macular } \\
\text { changes }\end{array}$ & Photopic ERG & $\begin{array}{l}\text { Combined (mesopic) } \\
\text { ERG }\end{array}$ & $\begin{array}{l}\text { Oscillatory potentials } \\
\text { ERG }\end{array}$ & $30 \mathrm{~Hz}$ flicker ERG & Scotopic ERG \\
\hline 1 & Severe & Abolished & Abolished & Abolished & Abolished & Abolished \\
\hline 2 & Severe & Abolished & Abolished & Abolished & Abolished & Abolished \\
\hline 3 & Mild & Diminished & Diminished & Diminished & Diminished & Diminished \\
\hline 4 & Moderate & $\begin{array}{l}\text { Severely } \\
\text { diminished }\end{array}$ & Severely diminished & Abolished & $\begin{array}{l}\text { Severely } \\
\text { diminished }\end{array}$ & Diminished \\
\hline 5 & Severe & Abolished & Abolished & Abolished & Abolished & Abolished \\
\hline 6 & Moderate & Abolished & Abolished & Severely diminished & $\begin{array}{l}\text { Severely } \\
\text { diminished }\end{array}$ & Abolished \\
\hline 7 & Severe & Abolished & Abolished & Abolished & Abolished & Abolished \\
\hline 8 & Severe & Abolished & Abolished & Abolished & Abolished & Abolished \\
\hline 9 & Severe & Abolished & Abolished & Abolished & Abolished & Abolished \\
\hline 10 & Severe & Abolished & ND & Abolished & Abolished & Abolished \\
\hline 11 & Moderate & ND & ND & ND & ND & ND \\
\hline 12 & Mild & Diminished & Diminished & Diminished & Diminished & Diminished \\
\hline 13 & Severe & Abolished & Normal & Diminished & Abolished & Normal \\
\hline 14 & Severe & $\begin{array}{l}\text { Severely } \\
\text { diminished }\end{array}$ & Diminished & Severely diminished & $\begin{array}{l}\text { Severely } \\
\text { diminished }\end{array}$ & $\begin{array}{l}\text { Severely } \\
\text { diminished }\end{array}$ \\
\hline 15 & Moderate & ND & ND & ND & ND & ND \\
\hline 16 & Severe & Abolished & Abolished & Abolished & Abolished & Abolished \\
\hline
\end{tabular}

Abbreviations: ERG, electroretinography, ND, not determined. ${ }^{a}$ Taken with Metrovision ERG. ERG values defined as following: normal (amplitude $<1$ $\mathrm{SD}$ ); borderline (diminished, 1-2 SD), abnormal (severely diminished $>2 \mathrm{SD}$ ) or not recordable (abolished, isoelectric line) according to the pre-established manufacturer values for the ERGs.

appearance, and RPE changes with retinal atrophy in the fovea. Out of the 16 cases, two (12.5\%) were classified with mild, four (25\%) with moderate and $10(62.5 \%)$ with severe maculopathy. The subjects did not show atrophy, paleness or glaucomatous changes in the optic nerve.

\section{Optic nerve analysis}

Optic nerve analysis showed normal ranges for all studied parameters (disc area, cup area, neuroretinal rim area and cup/disc ratio, and average retinal nerve fiber layer thickness), except for the last one in subjects 2 and 16 , who showed thinning in both eyes.

\section{Tomographic macular analysis}

Macular OCT analysis was performed in nine out of the 16 participants. All nine cases had some degree of foveal thinning. The mean foveal thickness was $133.9 \pm 22.8 \mu \mathrm{M}$ (range 109-174 $\mu \mathrm{M}$ ). Foveal changes ranged from small defects in the outer layers of the retina resembling macular microholes to severe atrophy with no retinal tissue left in the fovea. The ellipsoid layer was partially to totally affected in all nine cases. Seven subjects had RPE changes ranging from mild RPE disturbances to severe atrophy. Two cases presented a nonsignificant epiretinal membrane 


\section{$E R G$}

Flash-ERG was performed in eight out of the 16 participants. Results of the ERG are summarized in Table 3. All the eight subjects had alterations in the ERG. Photopic, $30 \mathrm{~Hz}$ flicker and oscillatory potentials were abnormal in all patients, amplitudes in these patients ranged from partially diminished to completely abolished. Scotopic and combined tests were altered in seven patients $(88 \%)$, in those with affected test, changes ranged from diminished to severely abolished. Only one case had normal dark-adapted responses, however this case presented an abnormal result in the light-adapted phases.

\section{Discussion}

SCA7 is an autosomal dominant disease caused by a polyQ expansion in the protein ataxin-7, characterized by progressive cerebellar ataxia and macular degeneration. ${ }^{16}$ SCA7 is considered to be rare, although founder effects have been reported in South Africa, Scandinavia, and Mexico. ${ }^{15,17}$

The pathology of this disorder include atrophy of the spinocerebellar pathways, pyramidal tracts, and motor nuclei in the brainstem and spinal cord, a cone-rod dystrophy of the retina, and ataxin-7 immunoreactive neuronal intranuclear inclusion. ${ }^{18}$ The spectrum of clinical severity in SCA7 ranges from infantile-onset with early death to elderly presentations of slowly progressive isolated ataxia depending on the number of CAG repetitions. $^{8}$

In this study, we carried out a thorough eye examination of 16 SCA7 cases. Patients with SCA7 often have visual symptoms that may precede, co-occur with, or follow the onset of ataxic symptoms. Our results did not support any order in the symptoms onset, as $56.25 \%$ of patients presented motor symptoms at onset of the disease rather than visual loss, whereas $12.5 \%$ experienced visual symptoms several years before the onset of neurological symptoms, and the rest had both at the same time.

Other findings, such as slow saccadic eye movements and ophthalmoplegia are common but not specific to SCA $77^{3,19}$ in our study, none of the patients showed ocular movement abnormalities. However, more specialized methodologies could potentially undercover fine oculomotor anomalies. ${ }^{20}$

In ophthalmological evaluation, endothelial examination through specular microscopy demonstrated significantly decreased cell density and altered morphological analysis when compared to healthy aged matched Mexican population. ${ }^{13}$ However, in clinical evaluation, we did not observe corneal edema or opacification in any case.

Interestingly, the correlation between ECD and number of CAG repeats showed an inverse relation, as $46 \%$ of the decrease on ECD is explained by the number of trinucleotide repeats. Trinucleotide repeats expansion has been associated to neurodegenerative diseases such as myotonic dystrophy and several SCAs ${ }^{21}$ and recently linked to Fuch's endothelial dystrophy. ${ }^{22,23}$ The mechanisms by which the expanded triplet repeats contribute to the degeneration of the corneal endothelium it is yet unknown, but may include RNA-mediated toxicity, haploinsufficiency or a combination of both. ${ }^{24}$ Furthermore, ECD is also inversely correlated with the severity of motor symptoms analyzed with the SARA scores. A previous description of ocular findings of SCA 7 subjects reported decreased ECD as an isolated; however, its relationship to motor symptoms and or genotype was not explored. ${ }^{10}$

Regarding retinal examination, our findings are consistent with reports of various degrees of maculopathy in the literature ${ }^{6,9,25}$ detecting the severe stage as the most prevalent $(62.5 \%)$. In the OCT imaging, all cases presented some degree of atrophy and ellipsoid layer loss; just one case was found with mild maculopathy.

Several studies have analyzed ERG in SCA7. In a previous study ${ }^{26}$ described 10 cases with SCA7, all they presented cone ERG changes; eight had genetic diagnosis confirmation, and in two of them the diagnosis was done clinically. Other authors ${ }^{19}$ studied five cases genetically confirmed, finding some patients with abnormal ERG may present minimal macular RPE changes in examination. ERG was performed in our study in eight cases, and all of them presented alterations in the photopic (cone-mediated), $30 \mathrm{~Hz}$ flicker and oscillatory potentials phases. Also, most of the patients (88\%) manifested some degree of alteration in the scotopic and combined phases that is similar to the cone-rod dystrophy described previously. ${ }^{19,26}$ Finally, the ERG performed in eight patients showed that all had some degree of abnormality in the photopic and oscillatory potentials.

SCA7 causes progressive retinal atrophy that eventually leads to blindness. It initially affects cone function, although rods are also affected later in the course of the disease. Degeneration of photoreceptive cells in the retina resulting in cone-rod dystrophy has been explained by non-cell-autonomous transneuronal pathology, as well as by the interaction of ataxin-7 with the transcription factor CRX, which is implicated in cell type-specific retinal degeneration. ${ }^{19,27}$ Ataxin-7 is widely expressed in neural and some non-neural human tissue. It is found in the cytoplasm and nucleus of nerve cells in regions either affected or unaffected by SCA7 pathology. 
Currently, the physiological function of the wild type form of ataxin-7 is not yet fully understood. ${ }^{28}$

In our case series, all patients presented a significant decrease in CDVA, and all but one showed changes in color vision test evaluation with Ishihara color plates. This correlates with both structural and functional assessment of the macula as OCT revealed photoreceptor dropout, specifically at the ellipsoid layer and with ERG response. Moreover the foveal thickness was quantitative and qualitative altered in all the patients. The OCT studies indicated that all patients had fovea atrophy or loss in the ellipsoid layer.

In conclusion, the correlation between eye deficits and motor symptoms could suggest that both impairments follow the same progression. This could be explained by similar degeneration mechanisms SCA7 is the result of a mutation located in the short arm of chromosome 3. It consists of 13 exons of genomic DNA, encodes the disease specific gene product ataxin-7, and causes SCA7 when its CAG repeat sequences are extended beyond 38. Current evidence points to the encoded protein with its enlarged polyglutamine tract as the main responsible. ${ }^{29-31}$

Possibly embryonic origin of endothelial cells from neural crest can contribute to the expression of mutations in ocular tissue; however, more research is needed to understand whether the motor and ocular degenerations are driven by the same faulty mechanisms.

The significant decrease in the ECD identified in specular microscopy even when the clinical examination is normal in patients with SCA 7 and its correlation with CAG repeats should be further explored in a prospective study. Should a progressive decline in ECD and motor symptoms be confirmed, specular microscopy could be considered a useful tool as an indicator of disease progression by a rapid and noninvasive method.

\section{Summary}

What was known before

- Spinocerebellar ataxia type 7 is characterized by progressive cerebellar ataxia, including dysarthria and dysphagia, and cone-rod and retinal dystrophy with progressive central visual loss resulting in blindness in affected adults.

What this study adds

- Our results suggest a correlation between cognitive impairment, motor and ocular level.

- The decreased endothelial cell density might be due to embryonic development.

\section{Conflict of interest}

The authors declare no conflict of interest.

\section{Acknowledgements}

Partially funded by DGAPA-PAPIIT IN221413 CONACYT 0220871 and Fund Research of Instituto de Oftalmologia Conde de Valenciana. The funding organizations had no role in the design or conduct of this research.

\section{References}

1 Rub U, Schols L, Paulson H, Auburger G, Kermer P, Jen JC et al. Clinical features, neurogenetics and neuropathology of the polyglutamine spinocerebellar ataxias type 1, 2, 3, 6 and 7. Prog Neurobiol 2013; 104: 38-66.

2 Paulson HL. The spinocerebellar ataxias. J Neuroophthalmol 2009; 29(3): 227-237.

3 Teive HA, Munhoz RP, Arruda WO, Lopes-Cendes I, Raskin S, Werneck LC et al. Spinocerebellar ataxias: genotype-phenotype correlations in 104 Brazilian families. Clinics (Sao Paulo) 2012; 67(5): 443-449.

4 Michalik A, Martin JJ, Van Broeckhoven C. Spinocerebellar ataxia type 7 associated with pigmentary retinal dystrophy. Eur J Hum Genet 2004; 12(1): 2-15.

5 Hernandez-Castillo C, Alcauter S, Galvez V, Barrios F, Yescas P, Ochoa A et al. Disruption of visual and motor connectivity in spinocerebellar ataxia type 7. Mov Disord 2013; 28(12): 1708-1716.

6 Enevoldson TP, Sanders MD, Harding AE. Autosomal dominant cerebellar ataxia with pigmentary macular dystrophy. A clinical and genetic study of eight families. Brain 1994; 117(Pt 3): 445-460.

7 Gouw LG, Kaplan CD, Haines JH, Digre KB, Rutledge SL, Matilla A et al. Retinal degeneration characterizes a spinocerebellar ataxia mapping to chromosome 3p. Nat Genet 1995; 10(1): 89-93.

8 Lebre AS, Brice A. Spinocerebellar ataxia 7 (SCA7). Cytogenet Genome Res 2003; 100(1-4): 154-163.

9 Hugosson T, Granse L, Ponjavic V, Andreasson S. Macular dysfunction and morphology in spinocerebellar ataxia type 7 (SCA 7). Ophthalmic Genet 2009; 30(1): 1-6.

10 Manrique RK, Noval S, Aguilar-Amat MJ, Arpa J, Rosa I, Contreras I. Ophthalmic features of spinocerebellar ataxia type 7. J Neuroophthalmol 2009; 29(3): 174-179.

11 Garcia-Velazquez LE, Canizales-Quinteros S, Romero-Hidalgo S, Ochoa-Morales A, Martinez-Ruano L, Marquez-Luna $\mathrm{C}$ et al. Founder effect and ancestral origin of the spinocerebellar ataxia type 7 (SCA7) mutation in Mexican families. Neurogenetics 2014; 15(1): 13-17.

12 Schmitz-Hubsch T, du Montcel ST, Baliko L, Berciano J, Boesch S, Depondt C et al. Scale for the assessment and rating of ataxia: development of a new clinical scale. Neurology 2006; 66(11): 1717-1720.

13 Molina-Rey D, Gomez A. Evaluación por décadas de edad del comportamiento de las células endoteliales corneales en población mexicana. Rev Mex Oftalmol 2005; 79(2): 93-100.

14 Stevanin G, David G, Durr A, Giunti P, Benomar A, Abada-Bendib $\mathrm{M}$ et al. Multiple origins of the spinocerebellar ataxia 7 (SCA7) mutation revealed by linkage disequilibrium studies with closely flanking markers, including an intragenic polymorphism (G3145TG/A3145TG). Eur J Hum Genet 1999; 7(8): 889-896. 
15 Magana JJ, Gomez R, Maldonado-Rodriguez M, Velazquez-Perez L, Tapia-Guerrero YS, Cortes H et al. Origin of the spinocerebellar ataxia type 7 gene mutation in Mexican population. Cerebellum 2013; 12(6): 902-905.

16 Garden GA, La Spada AR. Molecular pathogenesis and cellular pathology of spinocerebellar ataxia type 7 neurodegeneration. Cerebellum 2008; 7(2): 138-149.

17 Smith DC, Atadzhanov M, Mwaba M, Greenberg LJ. Evidence for a common founder effect amongst South African and Zambian individuals with Spinocerebellar ataxia type 7. J Neurol Sci 2015; 354(1-2): 75-78.

18 Martin JJ. Spinocerebellar ataxia type 7. Handb Clin Neurol 2012; 103: 475-491.

19 Martin J, Van Regemorter N, Del-Favero J, Lofgren A, Van Broeckhoven C. Spinocerebellar ataxia type 7 (SCA7) - correlations between phenotype and genotype in one large Belgian family. J Neurol Sci 1999; 168(1): 37-46.

20 Velazquez-Perez L, Rodriguez-Labrada R, Cruz-Rivas EM, Fernandez-Ruiz J, Vaca-Palomares I, Lilia-Campins J et al. Comprehensive study of early features in spinocerebellar ataxia 2: delineating the prodromal stage of the disease. Cerebellum 2014; 13(5): 568-579.

21 Larson E, Fyfe I, Morton AJ, Monckton DG. Age-, tissue- and lenght-dependent bidirectional somatic CAG-CTG repeat instability in an allelic series of R6/2 Huntington disease mice. Neurobiol Dis 2015; 76: 98-111.

22 Olejniczak M, Urbanek MO, Krzyzosiak WJ. The role of the immune system in triplet repeat expansion diseases. Mediat Inflamm 2015; 2015: 873860.

23 Soliman AZ, Xing C, Radwan SH, Gong X, Mootha VV. Correlation of severity of Fuchs endothelial corneal dystrophy with triplet repeat expansion in TCF4. JAMA Ophthalmol 2015; 133: 1386-1391.

24 Mootha VV, Hussain I, Cunnusamy K, Graham E, Gong X, Neelam $S$ et al. TCF4 triplet repeat expansion and nuclear RNA foci in Fuchs' endothelial corneal dystrophy. Invest Ophthalmol Vis Sci 2015; 56(3): 2003-2011.

25 Aleman TS, Cideciyan AV, Volpe NJ, Stevanin G, Brice A, Jacobson SG. Spinocerebellar ataxia type 7 (SCA7) shows a cone-rod dystrophy phenotype. Exp Eye Res 2002; 74(6): 737-745.

26 Miller RC, Tewari A, Miller JA, Garbern J, Van Stavern GP. Neuro-ophthalmologic features of spinocerebellar ataxia type 7. J Neuroophthalmol 2009; 29(3): 180-186.

27 Chen S, Peng GH, Wang X, Smith AC, Grote SK, Sopher BL et al. Interference of Crx-dependent transcription by ataxin-7 involves interaction between the glutamine regions and requires the ataxin-7 carboxy-terminal region for nuclear localization. Hum Mol Genet 2004; 13(1): 53-67.

28 Williams AJ, Paulson HL. Polyglutamine neurodegeneration: protein misfolding revisited. Trends Neurosci 2008; 31(10): 521-528.

29 Durr A. Autosomal dominant cerebellar ataxias: polyglutamine expansions and beyond. Lancet Neurol 2010; 9(9): 885-894.

30 Takahashi T, Katada S, Onodera O. Polyglutamine diseases: where does toxicity come from? what is toxicity? where are we going? J Mol Cell Biol 2010; 2(4): 180-191.

31 Yvert G, Lindenberg KS, Picaud S, Landwehrmeyer GB, Sahel JA, Mandel JL. Expanded polyglutamines induce neurodegeneration and trans-neuronal alterations in cerebellum and retina of SCA7 transgenic mice. Hum Mol Genet 2000; 9(17): 2491-2506. 